\title{
Usando física em quadrinhos para discutir a diferença entre inversão e reversão da imagem em um espelho plano $^{+*}$
}

\author{
Eduardo Oliveira Ribeiro de Souza ${ }^{1}$ \\ Instituto Oswaldo Cruz - Fiocruz \\ Deise Miranda Vianna \\ Instituto Oswaldo Cruz - Fiocruz \\ Instituto de Física - UFRJ \\ Rio de Janeiro - RJ
}

\section{Resumo}

Física em quadrinhos ( $F Q)$ é um projeto que busca promover entre os alunos e o professor discussões sobre fenômenos e assuntos científicos através de quadrinhos ou tirinhas de humor. Esses quadrinhos estão acompanhados de questões do cotidiano relacionadas à Física. O tema escolhido foi óptica, enfocando reflexão em espelhos planos. No desenvolvimento do conjunto de tirinhasquestões, a relação entre o texto e a imagem, sob uma perspectiva da teoria de quadrinhos, é levada em consideração e também pretende ajudar a trabalhar a capacidade crítica dos alunos. Assumindo a premissa de que elas já tiveram como objetivo instruir a sociedade, queremos usá-las no ensino de Física de forma reflexiva. Dentre as características dos quadrinhos ou tirinhas pode-se afirmar que apresentam alto nível de informação e podem ser ex-

Using Physics in comics to discuss the difference between inversion and reversal in a plane mirror image

* Recebido: maio de 2013.

Aceito: abril de 2014.

Apoio IOC/FIOCRUZ. 
ploradas pelo professor e discutidas com os alunos. As $H Q$ s e as tirinhas têm demonstrado estimular o desenvolvimento do hábito da leitura, enriquecendo o vocabulário do aluno. Por isso, acreditamos que essas tirinhas e as atividades propostas em sala de aula ajudaram na formação crítica dos alunos. Como os quadrinhos (ou tirinhas) estão imersos no nosso cotidiano, nada mais justo e apropriado do que utilizá-los para ensinar e apresentar a ciência e algumas situações cotidianas. Este artigo apresenta algumas tirinhas e seus objetivos no ensino de Física, além de explicitar como elas podem ser trabalhadas pelos professores.

Palavras-chave: Ensino de física. Tirinhas. Quadrinhos. Atividades investigativas. CTS. Óptica.

\begin{abstract}
Physics in Comics is a project that search to promote discussions among students and teacher about phenomena and scientific themes through comics or strips. These comics are accompanied by everyday questions related to Physics. The selected theme was Optics, focusing on reflection in plane mirrors. In developing the set of strips and questions, the relation between text and image, from the perspective of the theory of comics, is taken into consideration and also want to help work the critical skills of students. Assuming the premise that they have aimed to educate society, we want to use them in Physics teaching reflectively. Among the characteristics of comics or strips it can be said that they show high level of information, and they can be explored by the teacher and discussed with students. Comics have been shown to stimulate the development of the reading habits, thereby enriching the students vocabulary. Therefore, we believe that these strips and activities proposed in the classroom helped in the critical education of students. As the comics (or strips) are immersed in our daily lives, it is fair and appropriate to use them to teach and present Science and some everyday situations. This article presents some strips and objectives in Physics teaching, and to explain how they can be worked by teachers.
\end{abstract}


Keywords: Physics teaching. Comics. Investigative activities. STS.

Optics.

\section{Introdução}

As tirinhas de FQ foram criadas e produzidas por Souza (2012) durante o trabalho de conclusão de curso de licenciatura em Física da UFRJ. Elas têm o intuito de promover a discussão sobre fenômenos físicos. Nossa proposta é baseada no trabalho Concept Cartoons, de Brenda Keogh et al. (1998), que apresenta desenhos, em forma de pôster, nos espaços de propaganda do metrô em Londres. As ilustrações retratam situações do dia a dia associadas à pergunta "What do you think?" e tem o intuito de promover o entendimento e o interesse público sobre a ciência.

Assim como as tirinhas do metrô de Londres, o projeto Física em Quadrinhos apresenta situações do cotidiano e outras questões, que estão relacionadas com a situação ou com o fenômeno.

O título das historietas é um trocadilho entre a palavra História e Física. As histórias em quadrinhos (HQ) contam histórias, já as tirinhas de FQ "contam" Física daí seu nome. A Fig. 1 representa a marca das tirinhas.

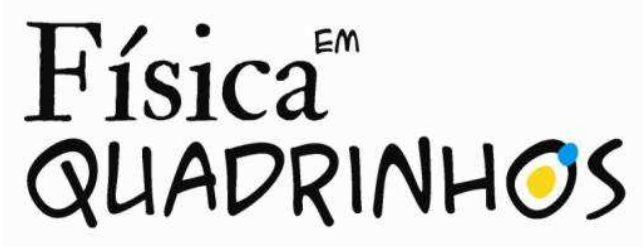

Fig. 1-Marca das tirinhas.

Um exemplo de tirinha de FQ é apresentado na Fig. 2. Reforçamos a ideia de Keogh et al. (1998) que sugerem que os personagens das tirinhas apresentem pontos de vistas alternativos sobre a ciência envolvida na situação e convidem os alunos a se juntar ao debate com eles.

No desenvolvimento das tirinhas levamos em consideração alguns pontos:

- As tirinhas devem por si só fazer uma pergunta, ou seja, a situação retratada nos quadrinhos deve estimular o interesse pelo fenômeno físico;

- Seguindo as características das tirinhas de jornal e que circulam na internet, os quadrinhos devem ter uma quantidade mínima de texto. Além disso, devem ser atrativas, nem muito infantis e nem muito sérias; 
- Elas devem expor alguns pontos de vista para que os alunos possam discutir entre eles, apresentando algumas concepções alternativas para que haja desconstrução desses conceitos. Os alunos devem ter a oportunidade de confrontar suas concepções com as concepções cientificamente corretas para notar os possíveis erros de suas informações e se corrigirem. E assim, construir seus conhecimentos;

- Foram consideradas as concepções espontâneas discutidas no trabalho de Almeida et al. (2007).

A FQ busca a formação cidadã do aluno e o desenvolvimento da capacidade de discutir e intervir nos problemas científicos da sociedade em que vive. Nas tirinhas do Física em Quadrinhos o protagonista das histórias é o fenômeno físico. Para Vergueiro (2004), os personagens secundários concorrem para destacar a atuação do protagonista, ou seja, os personagens secundários estão vivenciando esse fenômeno, para destacar o fenômeno físico.

O tema trabalhado em Física foi Óptica e mais espeficamente apresentaremos tirinhas com fenômenos observados em espelhos planos. Além disso, dividimos esse tema em cinco tópicos, em que cada um possui um conjunto de tirinhas com as suas respectivas perguntas e/ou atividades. Essa divisão seguiu a mesma sequência didática presente na maioria dos livros didáticos. Os tópicos são: (i) "inversão" da imagem; (ii) posição da imagem; (iii) campo visual; (iv) associação de espelhos e (v) curiosidade com espelhos e/ou reflexão. Apresentamos, na tabela a seguir, a distribuição dos quadrinhos por tema.

Tabela 1 - Relação de tirinhas por temas.

\begin{tabular}{c|c}
\hline Temas da Reflexão & $\begin{array}{c}\text { Número de } \\
\text { Tirinhas }\end{array}$ \\
\hline "Inversão" da Imagem & 5 \\
Posição da Imagem & 5 \\
Campo Visual & 4 \\
Associação de Espelhos & 2 \\
Curiosidades sobre Espelhos & 4 \\
\hline
\end{tabular}

Como uma das características mais importantes das tirinhas é o humor, algumas situações foram "exageradas" utilizando-se de certa licença poética. Nesse 
artigo, apresentaremos as tirinhas do tópico "Inversão" da Imagem. A Óptica foi escolhida como tema, por ser um tema pouco explorado em quadrinhos. Os temas mais recorrentes são a Mecânica e a Eletricidade.

Dentro da proposta dos quadrinhos do projeto, ao professor é dada a liberdade de trabalhar com ou sem as perguntas e/ou incorporar perguntas diferentes das perguntas originais. Além disso, recomendamos que elas sejam apresentadas aos alunos antes do conteúdo ser sistematizado pelo professor, porém também é dada a liberdade para ser aplicada antes, durante ou depois da sistematização.

\section{Nossos caminhos para a construção das FQs}

\section{II.1 Abordagem de ensino com ênfase em CTS}

Consideramos o enfoque em Ciência, Tecnologia e Sociedade - CTS - em nossas histórias. Ele vem sendo introduzido no ensino de ciências desde os anos sessenta, e tem como princípios: mostrar a ciência como uma atividade da humanidade e formar um aluno capaz de tomar decisões inteligentes e conscientes (SANTOS; MORTIMER, 2002). Essa perspectiva preconiza que a educação básica deve preparar o aluno para enfrentar o mundo em que vive, tornando-o um cidadão consciente e atuante. $\mathrm{O}$ aluno está imerso num mundo dominado pela ciência e pela tecnologia, por isso é justo que ele entenda as modificações causadas na sociedade por elas. Robert (1991, apud SANTOS; MORTIMER, 2002) atribui ao currículo com enfoque em CTS, que trata das relações entre as explicações científicas, planejamento tecnológico e solução de problemas, e tomada de decisão sobre os temas práticos de importância social.

A ciência deixa de ser ensinada pura e simplesmente para informar sua existência e passa a ser uma ferramenta que o aluno poderá usar para compreender o mundo e modificá-lo. O foco do "o que ensinar Física" passa a ser centrado em "para que ensinar Física". Cappechi (2004) também chama a atenção que para aprender Ciências é preciso saber também expressar-se em uma nova linguagem social, que é um importante espaço para discussão entre os alunos e entre o professor e o aluno na sala de aula. Proporciona tanto a identificação das ideias dos alunos a respeito dos fenômenos a serem estudados e é uma oportunidade para que estes ensaiem o emprego da linguagem científica escolar tão necessária na aprendizagem científica do aluno. Isto ajuda o aluno a desenvolver os conhecimentos e as habilidades, para que sua intervenção na sociedade seja positiva, tornando-o um cidadão alfabetizado científica e tecnologicamente. 


\section{II.2 Quadrinhos (ou tirinhas) como veículos de ensino}

As HQs já foram historicamente utilizadas para informar e como forma de comunicação. Para Eisner (1999a), as primeiras artes sequenciais (histórias em quadrinhos ou narrativas gráficas) vêm dos homens das cavernas, que usavam imagens primitivas como forma de linguagem. Os contadores de histórias das tribos de civilizações antigas eram os professores que, preservando o conhecimento, o passavam de geração para geração. Nos Estados Unidos, elas se apresentavam como de fácil linguagem e entendimento da língua inglesa para a maioria de sua população migrante, trabalhadora, semianalfabeta que precisava aprender o idioma do Novo Mundo (ARAGÃO, 2002). Como a mídia usava os personagens das HQs se comunicando num inglês mais coloquial e de fácil compreensão, isso alavancou significativamente a venda de jornais no final do século de XIX. Assim, é muito fácil entender porque é uma ferramenta de comunicação em massa tão importante e popular. Os quadrinhos têm temáticas diversas, desde ficção científica e fantástica, até as que ilustram fatos do cotidiano (ARAGÃO, 2002).

Keogh et al. (1998) apresentam a argumentação utilizando desenhos sobre situações do cotidiano no metrô em Londres com a questão "O que você pensa?", e afirma que os desenhos infantis e a fascinante questão ajudam a mostrar a importância da Física em nossas vidas e o poder de explicar porque as coisas acontecem assim. Os desenhos conceituais apresentam uma forma alternativa de ponto de vista sobre a ciência e a situação. Para Aragão (2002), o advento da internet e dos softwares gráficos ajudam ainda mais na produção e na utilização das tirinhas (ou quadrinhos) na educação, tornando a questão da acessibilidade ainda maior.

Apostamos que este tipo de comunicação possa contribuir efetivamente para a compreensão de fatos científicos. As histórias em quadrinhos se comunicam com o leitor através do argumento dos quadrinhos, por isso o enredo da história e o tema devem auxiliar nessa construção do discurso escolar. No caso das tirinhas de $\mathrm{FQ}$, acreditamos que, para uma sequência didática, a problematização deve ser mostrada através do enredo da história.

\section{II.3 Ensino por investigação como proposta metodológica}

Além de construirmos as HQs, apresentando temas relacionados ao ensino com enfoque CTS com objetivo de formar alunos críticos e atuantes na sociedade, é necessária uma proposta metodológica, o ensino de Ciências por investigação com as chamadas questões abertas ou problemas abertos. Para Azevedo (2004), em 
um curso de Física, torna-se de fundamental importância apresentar aos alunos problemas a serem resolvidos. Assumimos também a afirmação abaixo:

É preciso que sejam realizadas diferentes atividades, que devem estar acompanhadas de situações problematizadoras, questionadoras de diálogo, envolvendo a resolução de problemas e levando à introdução de conceitos para que os alunos possam construir seu conhecimento (CARVALHO, 1995 apud AZEVEDO, 2004).

Conforme Moreira (1983, apud AZEVEDO, 2004), a resolução de problemas que leva a uma investigação deve estar fundamentada na ação do aluno, de modo que ele tenha oportunidade de agir e deve ser acompanhada de ações e demonstrações que o levem a um trabalho prático.

"Para se alcançar este objetivo recomenda-se que a atividade concentre-se apenas nos aspectos desejados, com um planejamento cuidadoso que considere as ideias prévias dos estudantes a respeito da situação estudada, o tempo necessário para completar a atividade, as habilidades requeridas e aspectos ligados à segurança” (HODSON, 1988 apud BORGES, 2002, p. 301).

Azevedo (2004) salienta que o professor deve conhecer bem o assunto que será discutido na sala de aula para propor questões que façam o educando pensar e agir no problema. É necessário que esses aspectos sejam bem trabalhados pelo professor para que os objetivos sejam alcançados.

\section{Apresentando a questão da "inversão" da imagem num espelho plano}

Resumindo a proposta de ensino com HQs, com abordagem no enfoque CTS e proporcionando aos alunos a possibilidade de discussões, apresentamos a seguir alguns exemplos da Física em Quadrinhos. Outros exemplos podem ser vistos em Vianna e Bernardo (2012) e Souza (2012) ${ }^{2}$.

O senso comum diz que a imagem refletida no espelho plano é exatamente igual ao objeto. Porém isso é um equívoco. O objeto e a imagem não se sobrepõem, por isso, o termo para o fenômeno não é exatamente uma inversão, pois o

\footnotetext{
2 As tirinhas estão integradas ao conjunto de material produzido pelo grupo PROENFIS. Grupo que tem produzido e avaliado materiais para ensino de Física, e que publicou um livro Temas para o ensino de Física com abordagem CTS (Ciência, Tecnologia e Sociedade) (VIANNA; BERNARDO, 2012) apoio FAPERJ. As tirinhas fazem parte do capítulo 9 desse livro que se encontra online: www.proenfis.org.br do grupo PROENFIS.
} 
lado direito corresponde ao lado esquerdo e vice-versa. Na Física termo correto para esse fenômeno é reversão da imagem. Inversão, cientificamente falando, é virar de ponta cabeça. Porém, o termo "incorreto" está sendo usado para discussão desse assunto com os alunos. As tirinhas dessa unidade abordam questões e situações do dia a dia, nas quais a reversão é observada. Por exemplo, em ambulâncias, carros da Defesa Civil e do Corpo de Bombeiros. A situação está representada na Fig. 2.

A tirinha da Fig. 2 tem objetivo de iniciar a discussão sobre a reversão da imagem e também discutir o uso do termo "inversão". Além disso, propõe algumas atividades observacionais e experimentais.

Já a tirinha da Fig. 3 apresenta uma utilização muito comum da reversão da imagem - nos carros de emergência - com uma atividade prática e observacional. A tirinha abre uma reflexão muito interessante: a interpretação do menino está errada ou a menina se expressou de forma errada? E se existe a possibilidade de reproduzir a imagem imaginada pelo menino, fazendo um paralelo com a imagem refletida em superfície calma de lagos.

\section{Física $^{\mathrm{an}}$ QUADRINHOS "INVERSÃO" DAIMAGEMI}
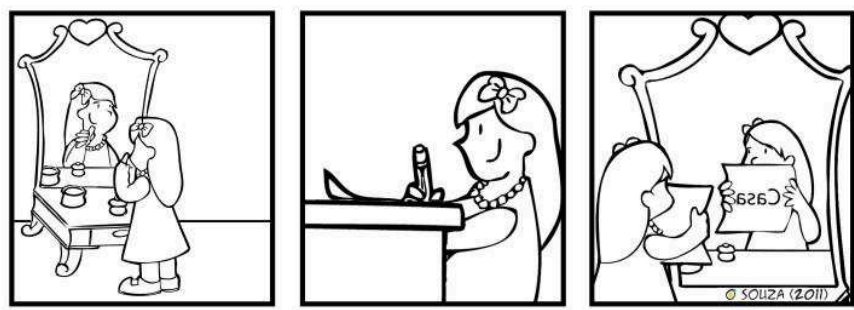

1) No primeiro quadrinho, qual braço da menina está levantado? Ena sua imagem?

2) Por que a palavra aparece "errada"? Escreva como ela deveria escrever para aparecer no "espelho" a palavra casa?

3) Vá a um espelho, e mexa seu corpo. Observe e anote o que está acontecendo com a sua imagem.

Fig. 2 - Exemplo de tirinha produzida sobre "inversão" da imagem. 
Física $^{\mathrm{en}}$

QUADRINHOS "INVERSÃO" DA IMAGEM II
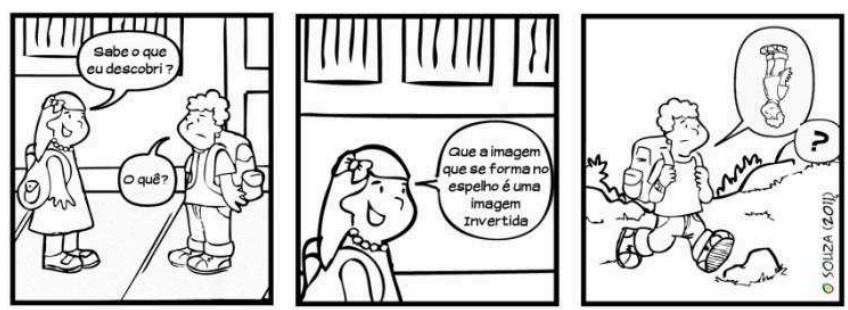

1) Porque a palavra impressa na frente de alguns veículos, como por exemplo a ambulância, é escrita ao contrário? Reproduza.

2) No quadrinho 3, o garoto teve uma interpretação de "inversão" da imagem. É possível reproduzir uma imagem assim, com um espelho plano? Como?

Fig. 3 - Tirinha produzida sobre "inversão” da imagem II.

Física $^{\text {en }}$

QUADRINHOS "INVERSÃO" DA IMAGEM III
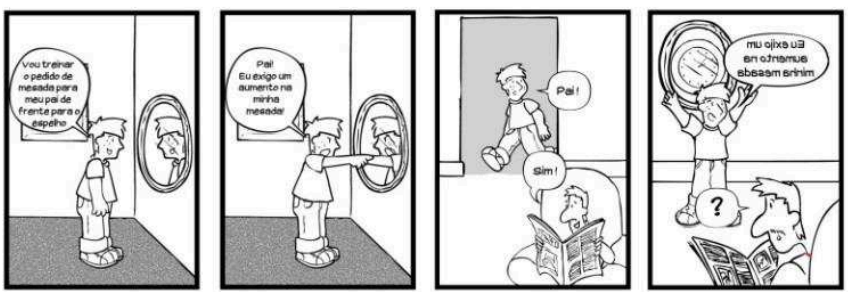

1) Imagine que você seja o pai do garoto. O que você faria para entender o que o garoto está dizendo?

2) Por que o espelho plano inverte a parte direita para a parte esquerda, mas não inverte a parte de cima para a parte de baixo?

3) Na parede da sala há um relógio de ponteiros no qual, em vez dos números, há pequenos traços. $\mathrm{Na}$ parede oposta àquela onde está o relógio existe um espelho plano. A figura ao lado mostra a imagem do relógio no espelho. Observando a imagem do espelho, responda: Que horas são no relógio?

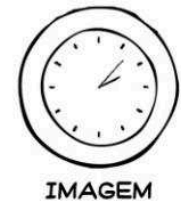

Fig. 4 - Exemplo de tirinha produzida sobre “inversão” da imagem.

Caderno Brasileiro de Ensino de Física, v. 31, n. 3, p. 601-613, dez. 2014. 
O conjunto tirinha-questão mostrado na Fig. 4 pode ser usado para discutir novamente as perguntas das primeiras tirinhas. Além disso, uma das questões apresentadas com a tirinha trata de um problema muito comum nos livros didáticos, em que há o reflexo de um relógio e se pergunta as horas marcadas, a partir da observação da imagem formada no espelho.

\section{Física ${ }^{\text {En }}$ QUADRINHOS "INVERSÃO" DAIMAGEMIV}
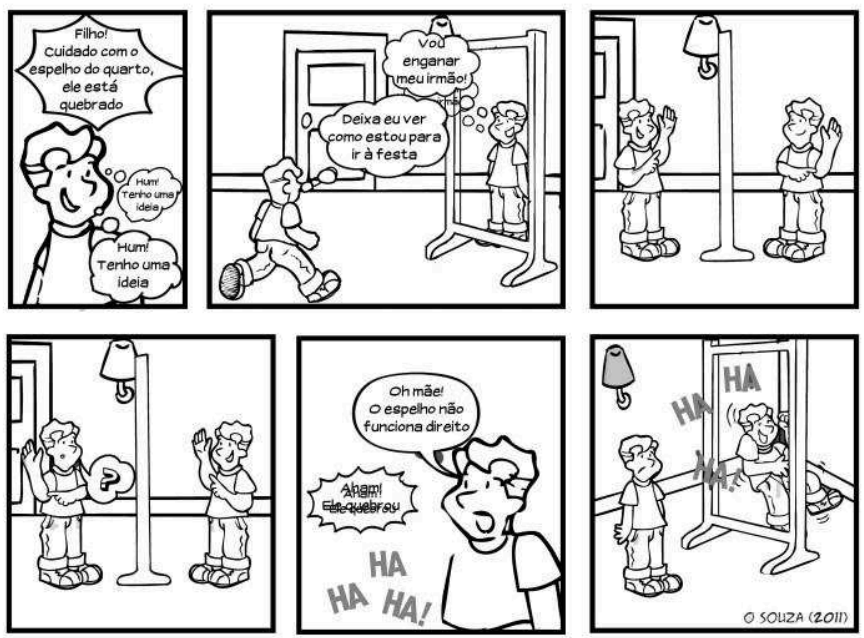

1) Escreva o seu nome, em letra de forma, à esquerda do espelho e na direita escreva a imagem do seu nome observada através de um espelho plano.

$$
\prod \begin{aligned}
& E \\
& S \\
& P \\
& E \\
& L \\
& H \\
& O
\end{aligned}
$$

2) Sem olhar no espelho, faça uma previsão de quais das seguintes letras têm uma imagem no espelho igual a si e quais têm uma imagem diferente.

\section{MVQCAGSRUNTO}

Em seguida, use o espelho para confirmar sua previsão.

Fig. 5 - Mais um exemplo de tirinha produzida sobre "inversão" da imagem. 
A tirinha da Fig. 5 mostra, de uma forma bem humorada, um garoto tentando enganar seu irmão gêmeo. Além disso, essa tirinha apresenta novas atividades, que vão reforçar as ideias discutidas nas outras tirinhas. As previsões propostas nessa tirinha podem ser exploradas pelo professor para avaliar se o aluno realmente entendeu o fenômeno.

Com o objetivo de explorar mais o assunto, a tirinha (Fig. 6) é proposta como complemento das primeiras tirinhas. Com uma situação engraçada, uma menina conversa sobre o espelho, e seu mau funcionamento. O professor pode perguntar se os alunos concordam com essa afirmação da menina. A tirinha também pergunta novamente sobre a questão de reversão, e o fato de a imagem e o objeto não serem exatamente iguais.

Essa tirinha apresenta também uma atividade investigativa sobre a observação de um dado entre dois espelhos. O professor pode sugerir que os alunos desenhem os resultados da observação.

\section{Física $^{\mathrm{km}}$}

QUADRINHOS "INVERSÃO" DAIMAGEMV
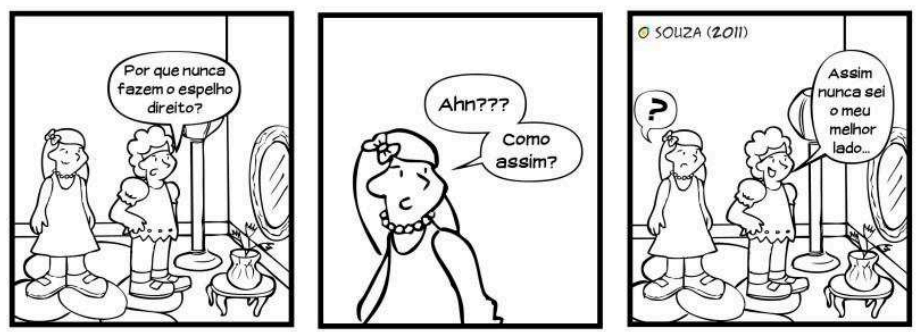

1) O que a menina quis dizer com: "fazer o espelho direito" $e$ "meu melhor lado"?

2) Vamos investigar imagens formadas em espelhos planos. Precisamos de um dado e dois espelhos planos de bolso. Coloque os espelhos um de frente para outro, e o dado no meio. Observe as imagens produzidas em ambos os espelhos. Faça um esquema mostrando como cada face se comporta diante do espelho. Que conclusões você pode tirar disso?

Fig. 6 - Outra tirinha produzida sobre "inversão" da imagem. 
Cada tópico de espelhos planos de Física em Quadrinhos segue uma sequencia ideal, porém elas são independentes entre si e podem ser utilizadas em qualquer ordem ou até sozinhas.

\section{Conclusão}

A forma de abordagem pensada para o presente projeto visa à formação cidadã dos alunos e que pode ser usada em qualquer disciplina, e em todos os níveis acadêmicos. O projeto foi desenvolvido a partir da pesquisa sobre os pressupostos do enfoque CTS, explicitando-os através dos resultados das pesquisas com atividades investigativas. A ênfase em CTS faz a discussão sobre os avanços tecnológicos ficarem mais comuns e próximos do aluno, de sua família e meio social. As atividades investigativas e a argumentação na sala de aula ajudam no desenvolvimento crítico do aluno e a busca de soluções para os problemas do dia a dia. Hoje observamos que os quadrinhos estão na moda com o surgimento de diversos geradores de tirinhas disponíveis na internet retratando situações cômicas do nosso cotidiano, porém ainda sem cunho científico ou pedagógico.

A Física em Quadrinhos é uma construção que visa atender aos pressupostos acima, proporcionando um ensino de Física mais contextualizado e porque não dizer, mais divertido. As tirinhas de FQ vêm sendo apresentadas em congressos e eventos científicos com os objetivos de divulgar, receber sugestões e críticas de outros pesquisadores e professores. O projeto está se estendendo e pretendemos produzir mais tirinhas e dos demais temas da Física, e contribuir na visão do uso de quadrinhos no ensino de Física. Além disso, algumas tirinhas estão sendo aplicadas em uma escola pública federal do Rio de Janeiro e em breve divulgaremos os resultados.

\section{Referências}

ALMEIDA, V. O.; CRUZ, C. A.; SOAVE, P. A. Concepções alternativas em Óptica. Porto Alegre: Instituto de Física - UFRGS, 2007.

ARAGÃO, O. A óptica sociopolítica da arte sequencial de Angelo Agostini em algumas páginas de $O$ cabrião (1866-1867) e da Revista Illustrada (18761898). 2002. Dissertação (Mestrado em Artes Visuais) - UFRJ, Rio de Janeiro. 
AZEVEDO, M. C. P. S. Ensino por investigação: Problematizando as atividades em sala de aula. In: CARVALHO, A.M. P. (Org). Ensino de Ciências - Unindo a Pesquisa e a Prática. São Paulo: Pioneira Thomson Learning, 2004. p.19-33.

BORGES, A. T. Novos rumos para o laboratório escolar de ciências. Caderno Brasileiro de Ensino de Física, v. 19, n. 3, p. 291-313, dezembro de 2002.

CAPPECHI, M. C. M. Argumentação numa aula de Física. In: CARVALHO, A.M. P. (Org). Ensino de Ciências - Unindo a Pesquisa e a Prática. São Paulo: Pioneira Thomson Learning, 2004. p. 59-76.

EISNER, W. Narrativas Gráficas: princípios e práticas da lenda dos quadrinhos. Tradução: Leandro Luigi Del Manto. 2. ed. São Paulo: Devir São Paulo: Martins Fontes, 1999.

KEOGH, B.; NAYLOR, S.; WILSON, C. Concepts cartoons: a new perspective on physics education. Physics Education, v. 33, n. 4, p. 219-224, 1998.

SANTOS, W. L. P.; MORTIMER, E. F. dos. Uma análise de pressupostos teóricos da abordagem C-T-S (Ciência - Tecnologia - Sociedade) no contexto da educação brasileira. Ensaio, Pesquisa em Educação em Ciências, v. 2, n. 2, p. 1-23, dez. 2002.

SOUZA, E. O. R. Física em Quadrinhos: Uma abordagem de ensino. 2012. Trabalho de Conclusão de curso (Licenciatura em Física) - Universidade Federal do Rio de Janeiro, Rio de Janeiro.

WALKER, J. O circo voador da Física. Rio de Janeiro: LTC, 2008.

VERGUEIRO, W. Como usar as histórias em quadrinhos na sala de aula. São Paulo: Contexto, 2004, p. 7-64.

VIANNA, D. M.; BERNARDO, J. R. R. (Org.). Temas para o ensino de Física com abordagem CTS (Ciência, Tecnologia e Sociedade). 1. ed. Rio de Janeiro: Bookmakers, 2012. 260p. v. 1. 